\title{
Diagnostic error in medicine: introduction
}

\author{
Eta S. Berner
}

Published online: 11 August 2009

(C) Springer Science+Business Media B.V. 2009

\section{Background}

In 1999 the Institute of Medicine (a division of the US National Academy of Sciences) published a landmark report indicating that from 44,000 to 98,000 deaths per year could be attributed to preventable medical errors (Kohn et al. 1999). Although the majority of errors related to therapy, including medication and surgical errors, the report identified a significant number of diagnostic errors. Until recently, most of the research in patient safety had not addressed these errors. In the last few years there has been increased recognition of the prevalence and severity of diagnostic errors. In 2007 the US Department of Health and Human Services' Agency for Healthcare Research and Quality (AHRQ) identified diagnostic errors as an area of special emphasis. (http:/grants.nih.gov/grants/guide/notice-files/ NOT-HS-08-002.html).

There is a background of research that is relevant to this newly recognized domain. Several patient safety and quality improvement researchers have focused on analyzing and characterizing errors and their impact, figuring what went wrong, why, and how can we fix it (Schiff 1994; Schiff et al. 2005; Croskerry 2000a, b, 2002, 2003a, b, c, 2005; Croskerry and Wears 2003; Cosby and Croskerry 2003; Graber et al. 2002; Graber 2004; Graber et al. 2005). In addition to a few patient safety/quality improvement researchers' interests in diagnostic errors, three other research domains have a longer history than the more recent interest in diagnostic errors within the patient safety arena, addressing fundamental questions about how humans make diagnoses and strategies to improve the process. These research domains are:

This special supplement to Advances in Health Sciences Education includes a selection of papers based on presentations at the conference on Diagnostic Error in Medicine, held in Phoenix Arizona, on May 31-June $1,2008$.

E. S. Berner $(\bowtie)$

Department of Health Services Administration, University of Alabama at Birmingham,

1675 University Blvd., Webb 544, Birmingham, AL 35294-3361, USA

e-mail: eberner@uab.edu 
- Medical Problem Solving-Beginning in the 1960s and assuming a dominant focus in medical education research in the 1970s and 1980s, but continuing today, the research on medical problem solving, includes research on expert-novice differences in problem solving, understanding clinical cognition, development of expertise, Problem-Based Learning (PBL), the development of problem solving simulations and other educational approaches to teach and measure medical problem solving. The focus of this research in many cases was to describe how clinicians think about diagnosis, "What is" in regard to diagnosis (Elstein et al. 1978; Berner 1984; Norman and Eva 2003, 2005; Patel et al. 2001, 1991; Neufeld et al. 1981; Norman et al. 1992).

- Normative decision making-About the same time as the research on medical problem solving began appearing in the literature, there was increasing focus on decision analytic approaches and other normative approaches to rationalize the decision making process of clinicians ("what ought to be"), in part spurred by the heuristics and biases literature indicating that the thinking of clinicians, like other humans, is often suboptimal and that to improve diagnosis (as well as therapeutic decision making) more systematic analytic methods need to be employed (Kahneman et al. 1982; Elstein 1999).

- Medical Informatics (specifically diagnostic decision support systems)_Also in the period from the 1960 s to the $1990 \mathrm{~s}$, as medical informatics as a profession was developing and computers were used somewhat more frequently by clinicians, medical informaticians began to address the question, "Can we design computer programs to assist physicians in diagnosis and do they actually work?" (Miller 1994; Berner et al. 1994, 1999; Berner and Maisiak 1999; Friedman et al. 1999, 2005)

There are several commonalities among these three research strains: (1) they all can inform the focus on diagnostic errors that is being emphasized in the patient safety movement; (2) they developed over a similar time period, but comparatively independently; (3) all three have begun to be applied to the area of diagnostic error by patient safety researchers. However, the relative isolation of these four research domains (medical problem solving, normative decision making, clinical diagnostic decision support research, and patient safety research) combined with the increased interest in addressing diagnostic errors highlights the need for more communication among researchers in these areas. The inaugural conference on Diagnostic Error in Medicine in May 2008 addressed that need by creating an environment that encouraged collaboration among those interested in the problem of diagnostic errors. More importantly, it was the first national effort to bring researchers from the disparate research domains together to address this important issue.

\section{Conference on diagnostic error in medicine: May 31-June 1, 2008}

Prior to the May conference, the Conference organizing committee met in Naples, Florida to respond to an analysis of diagnostic errors prepared by the conference co-chairs Berner and Graber (Berner and Graber 2008) The meeting and Drs. Berner and Graber's work, and the special supplement to the American Journal of Medicine that resulted from it (full text of the supplement is available online at http://www.ajmselect.com/issues/contents?issue key=S0002-9343(08)X0007-5) was funded by the Paul Mongerson Foundation within the Raymond James Charitable Endowment Fund. Mr. Mongerson's interests in diagnostic errors stems from a personal incident (Mongerson 1995) and he has been active supporter of informatics efforts to reduce diagnostic errors. Mr. Mongerson also spoke at the May 
conference which was co-sponsored by the Agency for Healthcare Research Quality (AHRQ) and the American Medical Informatics Association (AMIA).

The conference speakers included nationally and internationally recognized experts representing the four research areas. There were also smaller breakout groups where participants interacted with experts in diagnostic errors that occur in specific settings. This supplement includes a selection of the papers presented at the conference.

Keynote addresses: the challenge of diagnostic errors

There were two keynote addresses representing the Patient Safety perspective (Robert M. Wachter, MD) and the other research areas (Arthur S. Elstein, PhD, who over the course of his career has contributed significantly to the medical problem solving, normative decision making, and informatics literature). Dr. Wachter summarized his presentation in his blog (http://community.the-hospitalist.org/blogs/wachters_world/archive/2008/06/02/whydiagnostic-errors-don-t-get-any-respect-and-what-can-be-done-about-it.aspx) and Dr. Elstein's address is the lead article in this supplement. These authors address the research challenges in studying diagnostic errors and also in getting the patient safety issues related to diagnostic errors the attention they deserve.

Perspectives on clinical decision making

This part of the conference was introduced by Vimla Patel, $\mathrm{PhD}$, who is an experienced cognitive science, medical education and informatics researcher. The papers in this supplement by Robert L. Wears, MD, MS, Patrick Croskerry, MD, PhD, and Geoffrey R. Norman, PhD reflect a variety of perspectives on this topic. At the conference (but not included in this supplement), Mark Roberts, MD, presented how the normative decision making approach applies to diagnostic decision making. This set of articles illustrates that despite decades of work on a variety of models of clinical decision making, there is still controversy as to how to use the research data to improve decision making.

Diagnostic errors: settings and sources

Breakout groups on Errors in Pathology (Steven Raab, MD and Dana Grzybicki, PhD), Emergency Settings (Robert L. Wears, MD and Patrick Croskerry, $\mathrm{PhD}$ ) and Ambulatory Care (Hardeep Singh, MD and Saul Weingart, MD, PhD), as well as Laboratory Errors (Terry Wahls, MD and Peter Cram, MD) and visual diagnosis were conducted. The summary of the sessions on Laboratory Errors and Errors in Ambulatory Care are included in this supplement. The articles included in this section demonstrate both the issues related to diagnostic errors that transcend settings as well as the unique issues related to studying and improving laboratory errors and errors in ambulatory care settings.

Educational approaches to reducing diagnostic error

Educational interventions are commonly suggested as a primary strategy to reduce diagnostic errors. In the supplement, Mark L. Graber, MD presents a compilation of the educational approaches to reducing diagnostic error. In the second paper in this section, Kevin Eva, $\mathrm{PhD}$, presents results of studies that evaluate the effectiveness of some of these approaches. Despite the variety of educational strategies, in many cases the research shows 
unexpected outcomes, indicating that additional research is needed to identify truly effective educational interventions.

Reducing diagnostic errors with clinical decision support

A second strategy for reducing diagnostic errors is increasing the use of computer-based clinical decision support. The papers included in this supplement represent a look into the future as well as the history of clinical diagnostic decision support. The introduction to this section by Robert A. Greenes, MD, PhD, provides an interesting perspective on how diagnosis and decision support for diagnosis will be changed in the era of "personalized medicine," with increased knowledge about the association of genetics and disease. Randolph A. Miller, MD, a pioneer in the development of computer-based clinical diagnostic decision support systems, provides a historical overview of the development of these systems as well as a look into their future. His comprehensive bibliography includes the major work evaluating these diagnostic systems. Conference presentations by Gordon D. Schiff, MD, on the use of clinical documentation for decision support and Charles P. Friedman, MD on evaluation perspectives for decision support are not included in this supplement.

\section{Next steps for research}

The last part of the conference was spent in small groups synthesizing the previous sessions and identifying areas for further research. In this supplement, Mark L. Graber, MD summarizes these next steps for further research on reducing diagnostic errors. Dr. Graber illustrates both what we know from previous research and the questions that are unanswered. As will be obvious from Dr. Graber's synthesis, despite almost a half century of research from four different research traditions, there is still much more to learn about the factors influencing diagnostic errors and the strategies to reduce them.

Acknowledgments The conference on Diagnostic Error in Medicine and this supplement were funded in part by grant \# 1R13HS017406-01 to the University of Alabama at Birmingham. The assistance of Ms. Marcie Battles and Ms. Joy Ptacek with the conference logistics was much appreciated by the conference organizing committee.

\section{References}

Berner, E. S. (1984). Paradigms and problem-solving: A literature review. Journal of Medical Education, 59(8), 625-633.

Berner, E. S., \& Graber, M. L. (2008). Overconfidence as a cause of diagnostic error in medicine. American Journal of Medicine, 121(Suppl. 5), S2-S23.

Berner, E. S., \& Maisiak, R. S. (1999). Influence of case and physician characteristics on perceptions of decision support systems. Journal of the American Medical Informatics Association, 6(5), 428-434.

Berner, E. S., Maisiak, R. S., Cobbs, C. G., \& Taunton, O. D. (1999). Effects of a decision support system on physicians' diagnostic performance. Journal of the American Medical Informatics Association, 6(5), 420-427.

Berner, E. S., Webster, G. D., Shugerman, A. A., et al. (1994). Performance of four computer-based diagnostic systems. New England Journal of Medicine, 330(25), 1792-1796.

Cosby, K. S., \& Croskerry, P. (2003). Patient safety: A curriculum for teaching patient safety in emergency medicine. Academic Emergency Medicine, 10(1), 69-78.

Croskerry, P. (2000a). The cognitive imperative: Thinking about how we think. Academic Emergency Medicine, 7, 1223-1231. 
Croskerry, P. (2000b). The feedback sanction. Academic Emergency Medicine, 7, 1232-1238.

Croskerry, P. (2002). Achieving quality in clinical decision making: Cognitive strategies and detection of bias. Academic Emergency Medicine, 9, 1184-1204.

Croskerry, P. (2003a). Cognitive forcing strategies in clinical decision making. Annals of Emergency Medicine, 41, 110-120.

Croskerry, P. (2003b). The importance of cognitive errors in diagnosis and strategies to minimize them. Academic Medicine, 78, 775-780.

Croskerry P. (2003c). When diagnoses fail. New insights, old thinking. The Canadian Journal of CME, 15(11), 79-87.

Croskerry, P. (2005). Diagnostic failure: A cognitive and affective approach. Advances in Patient Safety: From Research to Implementation Volume 2, AHRQ Publication No. 0500212 Feb 2005 Agency for Healthcare Research and Quality, Rockville, MD http://www.ahrq.gov/qual/advances/.

Croskerry, P., \& Wears, R. L. (2003). Safety errors in emergency medicine. In V. J. Markovchick \& P. T. Pons (Eds.), Emergency medicine secrets. Philadelphia, PA: Hanley \& Belfus.

Elstein, A. S. (1999). Heuristics and biases: Selected errors in clinical reasoning. Academic Medicine, 74, 791-794.

Elstein, A. S., Shulman, L. S., \& Sprafka, S. A. (1978). Medical problem solving. An analysis of clinical reasoning. Cambridge, MA: Harvard University Press.

Friedman, C. P., Elstein, A. S., Wolf, F. M., et al. (1999). Enhancement of clinicians' diagnostic reasoning by computer-based consultation: A multisite study of 2 systems. JAMA, 282(19), 1851-1856.

Friedman, C. P., Gatti, G. G., Franz, T. M., et al. (2005). Do physicians know when their diagnoses are correct? Journal of General Internal Medicine, 20(4), 334-339.

Graber, M. L. (2004). Diagnostic error in medicine: A case of neglect. Joint Commission Journal on Quality and Patient Safety, 31(2), 112-119.

Graber, M. L., Franklin, N., \& Gordon, R. (2002). Reducing diagnostic error in medicine: What's the goal? Academic Medicine, 77, 981-992.

Graber, M. L., Franklin, N., \& Gordon, R. R. (2005). Diagnostic error in internal medicine. Archives of Internal Medicine, 165, 1493-1499.

Kahneman, D., Slovic, P., \& Tversky, A. (1982). Judgement under uncertainty: Heuristics and biases. Cambridge, England: Cambridge University Press.

Kohn, L., Corrigan, J. M., \& Donaldson, M. (1999). To err is human; building a safer health system. Washington, DC: National Academies Press.

Miller, R. A. (1994). Medical diagnostic decision support systems-past, present, and future: A threaded bibliography and brief commentary. Journal of the American Medical Informatics Association, 1(1), $8-27$.

Mongerson, P. (1995). A patient's perspective of medical informatics. Journal of the American Medical Informatics Association, 2(2), 79-84.

Neufeld, V. R., Norman, G. R., Feightner, J. W., \& Barrows, H. S. (1981). Clinical problem-solving by medical students: A cross-sectional and longitudinal analysis. Medical Education, 15(5), 315-322.

Norman, G. R., Coblentz, C. L., Brooks, L. R., \& Babcook, C. J. (1992). Expertise in visual diagnosis: A review of the literature. Academic Medicine, 67(10), S78-S83.

Norman, G. R., \& Eva, K. W. (2003). Doggie diagnosis, diagnostic success and diagnostic reasoning strategies: An alternative view. Medical Education, 37(8), 676-677.

Norman, G. R., \& Eva, K. W. (2005). Does clinical experience make up for failure to keep up to date? ACP Journal Club, 142(3), A8-A9.

Patel, V. L., Arocha, J. F., \& Kaufman, D. R. (2001). A primer on aspects of cognition for medical informatics. Journal of the American Medical Informatics Association, 8, 324-343.

Patel, V. L., Groen, G. J., \& Norman, G. R. (1991). Effects of conventional and problem-based medical curricula on problem solving. Academic Medicine, 66(7), 380-389.

Schiff, G. D. (1994). Commentary: Diagnosis tracking and health reform. American Journal of Medical Quality, 9(4), 149-152.

Schiff, G. D., Kim, S., Abrams, R., et al. (2005). Diagnosing diagnosis errors: Lessons from a multiinstitutional collaborative project for the diagnostic error evaluation and research project investigators. Advances in Patient Safety: From Research to Implementation Volume 2, AHRQ Publication No. 0500212 Feb 2005 Agency for Healthcare Research and Quality, Rockville, MD http://www.ahrq. gov/qual/advances/. 